\title{
Prevalence of Dental Caries and Treatment Needs among Adult Population of Mangalore Taluk - A Pilot Survey
}

\author{
Mallika Shetty ${ }^{1}$, Pradeep Kumar², Uma Mayoor Prabhu³, Vinayak Kamath Bola ${ }^{4}$ Sanath Kumar Shetty ${ }^{5}$ \\ ${ }^{1}$ Department of Prosthodontics, Yenepoya Dental College, Yenepoya (Deemed to be University), Mangalore, \\ Karnataka, India. ${ }^{2}$ Department of Conservative Dentistry \& Endodontics, Yenepoya Dental College, Yenepoya \\ (Deemed to be University), Mangalore, Karnataka, India. ${ }^{3}$ Department of Prosthodontics, Yenepoya Dental \\ College, Yenepoya (Deemed to be University), Mangalore, Karnataka, India. ${ }^{4}$ Department of Public Health \\ Dentistry, Goa Dental College and Hospital, Bambolim, Goa, Karnataka, India. ${ }^{5}$ Department of Prosthodontics, \\ Yenepoya Dental College, Yenepoya (Deemed to be University), Mangalore, Karnataka, India.
}

\section{ABSTRACT}

\section{BACKGROUND}

Dental caries remains the most common oral disease affecting a considerable proportion of people worldwide. It not only causes damage to the tooth, but is also responsible for several morbid conditions of the oral cavity and other systems of the body. Without treatment, caries can proceed and destroy the tooth leading to infection of dental pulp. We wanted to evaluate the prevalence of dental caries and treatment needs among adult rural population.

\section{METHODS}

619 participants aged 18 years and above from peripheral health centres were examined to determine the prevalence of caries and treatment needs. A pretested proforma was used for data collection. Collected data was analysed using Chi Square test. $\mathrm{P}<0.05$ was considered as significant.

\section{RESULTS}

No significant difference was found in the mean number of teeth affected by caries between the two age groups ( $<40$ years $\&>40$ years) $(p=0.352)$, between genders $(\mathrm{p}=0.704)$ and education levels $(\mathrm{p}=0.983)$. When treatment needs (TN) was considered, maximum 2 surface fillings were needed in both the age groups $(<40$ years $45.6 \%$ \& >40 years $54.4 \%$ ). Various treatment needs prevailed among participants of different education level.

\section{CONCLUSIONS}

Oral health educative programs may change the attitude of an individual and population as a whole towards maintenance of oral health.
Corresponding Author: Dr. Pradeep Kumar, Department of Conservative Dentistry \& Endodontics, Yenepoya Dental College, Yenepoya, Deemed to Be University, Mangalore-575018, Karnataka, India. E-mail:drkumars8@gmail.com

DOI: $10.14260 / j e m d s / 2020 / 450$

How to Cite This Article:

Shetty M, Kumar P, Prabhu UM, et al. Prevalence of dental caries and treatment needs among adult population of Mangalore taluk- a pilot survey. J. Evolution Med. Dent. Sci. 2020;9(29):2068-2071, DOI: $10.14260 / j e m d s / 2020 / 450$

Submission 15-04-2020,

Peer Review 12-06-2020,

Acceptance 19-06-2020,

Published 20-07-2020.

Copyright (C) 2020 JEMDS. This is an open access article distributed under Creative Commons Attribution License [Attribution 4.0 International (CC BY 4.0)]

\section{KEY WORDS}

Caries, Education, Oral Health, Adult Population, Treatment Need 


\section{BACKGROUND}

Oral health is the mirror of general health. Hence, maintaining a good oral health becomes utmost important for general health and wellbeing of a person. Dental caries remains the most common oral disease affecting a considerable proportion of people worldwide. It not only causes damage to the tooth but is also responsible for several morbid conditions of the oral cavity and other systems of the body. ${ }^{1}$

Dental caries is an irreversible microbial disease of the calcified tissues of the teeth, characterized by demineralization of the inorganic portion and destruction of the organic substance of the tooth, which often leads to cavitation. ${ }^{2}$

Developing countries have a high prevalence of caries, which has been associated with sucrose in modern diet. Without treatment, caries can proceed and destroy the tooth and lead to infection of dental pulp. ${ }^{3}$ Lot of variations in the trends with regard to the prevalence and the severity of dental caries have been reported. Its prevalence in a population is influenced by a number of risk factors such as age, sex, ethnic group, dietary patterns and oral hygiene habits as well as affected by income, education and social environment. ${ }^{4}$

Pretty much every person of each geographic territory on the planet give some proof of dental caries influencing both the genders, all races, all financial status of all age gatherings. ${ }^{5}$ It causes agony and distress, yet in addition also, places a budgetary weight. 6 Many don't have the imperative information or qualities to perceive the significance of oral hygiene and don't practice suitable oral hygiene or pick an appropriate diet. Some might be increasingly susceptible to dental caries in the event that they have propensity for eating cariogenic snacks and other unfortunate dietary patterns. ${ }^{7}$

Presence of cariogenic bacteria, use of refined carbohydrates, poor oral hygiene maintenance are among the major factors resulting in dental caries. Dental plaque provides the environment for bacteria to form acid, which causes demineralization of hard tissues of teeth.

The prevention of dental caries has for quite some time been considered as a significant errand for the wellbeing. Research keeps on gaining ground in recognizing the prescribed procedures for diagnosing, treating, and forestalling dental caries. Conventional methodologies for treating carious are being supplanted by more up to date techniques that stress infection counteraction and preservation of tooth structure. ${ }^{6}$

Dental caries can be prevented by reducing demineralizing factors such as improving oral hygiene, dietary measures etc and by increasing protective factors such as using pit and fissure sealants, remineralizing agents etc.

Most of the studies done so far were involving school children. ${ }^{6,8,9}$ By and large the general impression is that dental caries has expanded in predominance in urban and cosmopolitan population in the course of the last couple of decades. Anyway, there is less picture so far with respect to the disease status in rural and backward areas of nation. ${ }^{6}$ Hence the present study focused on adults, with an aim to evaluate the prevalence of dental caries and treatment needs.

\section{METHODS}

A cross sectional study was carried out on 619 participants aged 18 years and above. Caries prevalence in Dakshina Kannada District, Karnataka is $40 \%$. Based on this sample size was calculated as 600 . While collecting the data 619 participants were examined. A purposive sampling was done in peripheral health centres of Mangalore taluk, Karnataka State, India. Ethical clearance for the study was obtained from the Yenepoya University Ethical Committee, Mangalore, Karnataka. The participants were examined to determine the prevalence of caries and treatment needs.

\section{Inclusion Criteria}

1. The population in the age range of 18 years and above.

2. Presence of caries.

3. Consent for participation in the study.

\section{Exclusion Criteria}

1. Patients who refused dental check-up

2. Patients who did not have caries

A pretested proforma was used for data collection. It consisted of two parts-the 1st part recorded data on sociodemographic factors (age, gender, educational status, occupation etc.), while the $2^{\text {nd }}$ part contained a section of the World Health Organization (WHO) Oral Health Assessment Form $(1997)^{8}$ to record the dentition status and treatment need. TN1-One Surface Filling, TN2-Two Surface Filling, TN3Crown, TN4-Veneer, TN5-Root Canal Treatment and TN6Extraction.

\section{Statistical Analysis}

The data collected was entered into Microsoft excel spreadsheet and analyzed using IBM SPSS Statistics, Version 22 (Armonk, NY: IBM Corp). Descriptive data were presented in the form of frequency, percentage for categorical variables and in the form of mean and standard deviation for continuous variables. Comparisons of the categorical variables were performed using the chi square test. $\mathrm{P}$ value $<0.05$ was considered as statistically significant.

\section{RESULTS}

Mean number of teeth affected by caries in age group below 40 years is $2.70 \pm 1.98$. Mean number of teeth affected by caries in age group above 40 years is $2.83 \pm 1.89$. No significant difference was found in the mean number of teeth affected by caries between two age groups.

Table1 shows the distribution of caries and treatment needs according to age. When treatment needs (TN) was considered maximum 2 surfaces filling were needed in both the age groups (above and below 40 years). The need for crown was lesser in below 40 years. The need for RCT was lesser in above 40 years. 
Table 2 shows the distribution of caries and treatment needs according to gender. No significant difference was found between numbers of teeth affected by caries between genders. Two surface restorations were found to be higher among males and females.

Table 3 shows the distribution of caries and treatment needs according to education: Need for One surface filling was predominantly high in primary educated. Two surface filling was also predominantly high in primary educated. Need for Crown was high in Pre-University (PU) educated subjects followed by illiterates. Need for Veneer was high in primary educated and in graduates.

Need for RCT was high in primary educated. Need for Extraction was predominantly high in graduates.

Table 4 shows the distribution of caries according to tooth brushing. Treatment need for study population who brushed thrice daily was least, compared to those who brushed once or twice daily.

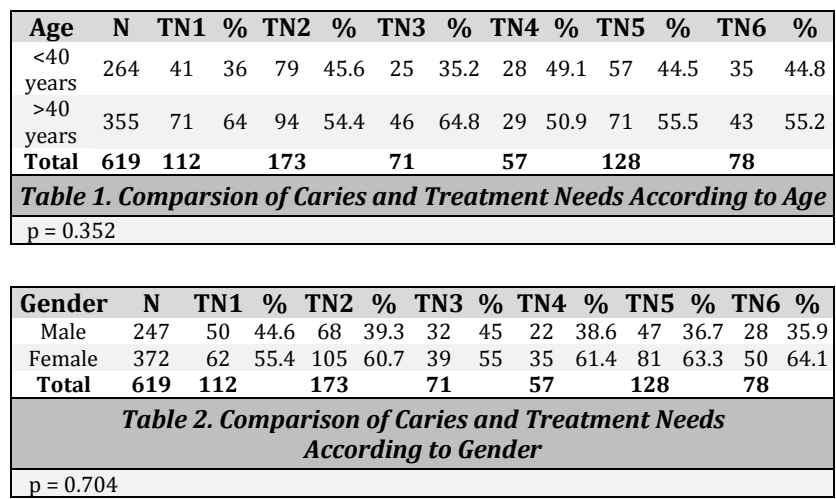

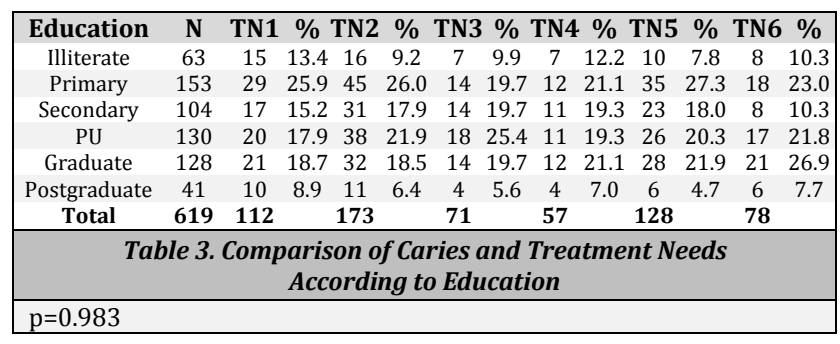

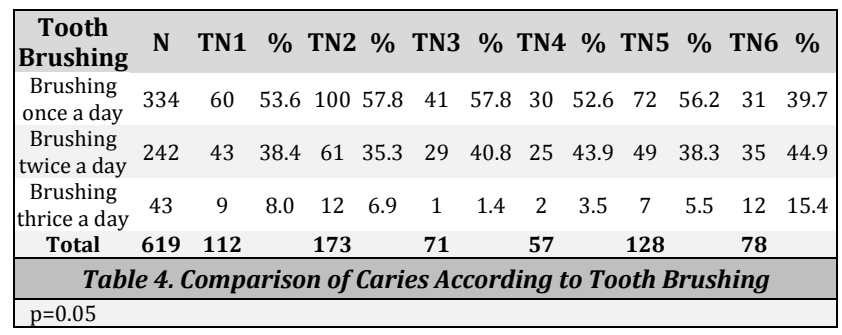

\section{DISCUSSION}

Dental caries being the most common and prevalent disease of oral cavity in the countries where the lower and middle class people occupy a major population. ${ }^{1,2}$ A pilot study was carried out in rural areas of Mangalore taluk, Karnataka State, India, including a sample size of 619 with (247) Males and (372) females to assess prevalence of dental caries and treatment need. The study revealed that there was a slight increase in number of teeth affected by caries in the age group of above 40 years. This could be attributed to poor oral hygiene maintenance and negligence of visiting dentist as age advances due to social responsibilities. The results found were in consistence with studies conducted earlier. ${ }^{1,3,4}$

When treatment needs ( $\mathrm{TN}$ ) was considered maximum 2 surfaces filling were needed in both the age groups (above and below 40 years). This could be attributed to no coverage of dental treatment under health insurance policies in India. Poor socio-economic status, difficult accessibility to the treatment in rural areas, more number and distribution of dentists in urban areas have been implicated in poor utilization of oral care services in rural areas of developing countries.6,8-10

When distribution of caries and treatment needs according to gender was assessed, it was found out that female had higher treatment need than males, which is in accordance to the study by Shubha et al. ${ }^{11}$ But a study by Patro et al showed no significant difference between males and females with caries. $^{12}$

When distribution of caries and treatment needs according to education was assessed, one surface filling and two surface filling was predominantly high in primary educated. Lack of awareness and poor oral hygiene maintenance and consuming diet containing refined sugar could be the probable reason for caries.

Need for Crown was increased in PU educated subjects probably because of lack of awareness of restoring the decayed tooth back to normal form and function.

Need for Veneer was increased in primary educated and graduates due to lack of awareness of esthetic appearance of teeth.

Requirement for RCT was increased in primary educated. Higher the education higher the knowledge of caries and restorative procedures. ${ }^{13}$ The study population with secondary education and above had better knowledge for saving the teeth with different treatment need options.

Extraction was predominantly high in graduates. The busy schedule of the graduates, either due to education or employment, might have resulted in unattended badly decayed teeth. These unrestorable tooth would have led to the need for extraction.

Treatment need for study population who brushed thrice daily was least compared to those who brushed once or twice daily, which reveals that better the oral hygiene maintenance, lesser is the treatment need.

In general, people have an inconsistent knowledge level on oral hygiene methods and diet recommended for prevention of dental caries due to education level, social-economical profile, interest level and learning opportunity. In this context, social projects and/or programs are important to evaluate the patients' knowledge and establish educative parameters, aiming to reduce the number of tooth losses over the years. ${ }^{14}$

\section{CONCLUSIONS}

It is necessary to evaluate oral hygiene habits and knowledge level of the target population in order to institute effective programs. These oral health educative programs may change 
the attitude of an individual and population as a whole towards maintenance of oral health.

\section{REFERENCES}

[1] Chakraborty M, Saha JB, Bhattacharya RN. Epidemiological correlates of dental caries in an urban slum of West Bengal. Indian J Public Health 1997;41(2):56-60.

[2] Shafer WG. Textbook of oral pathology. $8^{\text {th }}$ edn. New Delhi: Elsevier 2017: p. 359.

[3] Peter S. Essentials of public health dentistry. $5^{\text {th }}$ edn. New Delhi: Arya Medi Publishing House Pvt. Ltd. 2013: p. 257.

[4] Sudha P, Bhasin S, Anegundi RT. Prevalence of dental caries among 5-13-year-old children of Mangalore city. J Indian Soc Pedod Prev Dent 2005;23(2):74-9.

[5] Moses J, Rangeeth BN, Gurunathan D. Prevalence of dental caries, socio-economic status and treatment needs among 5 to 15 year old school going children of chidambaram. J Clin Diagn Res 2011;5(1):146-51.

[6] Damle SC, Patel AR. Caries prevalence and treatment need amongst children of Dharavi, Bombay, India. Community Dent Oral Epidemiol 1994;22(1):62-3.

[7] Oredugba FA, Akindayomi Y. Oral health status and treatment needs of children and young adults attending a day centre for individuals with special health care needs. BMC Oral Health 2008;8:30.

[8] Dash JK, Sahoo PK, Bhuyan SK, et al. Prevalence of dental caries and treatment needs among children of Cuttack (Orissa) J Indian Soc Pedod Prev Dent 2002;20(4):139-43.

[9] Saravanan S, Kalyani V, Vijayarani MP, et al. Caries prevalence and treatment needs of rural school children in Chidambaram Taluk, Tamil Nadu, South India. Indian J Dent Res 2008;19(3):186-90.

[10] World Health Organization. Oral health surveys: basic methods. 4th edn. Geneva, Switzerland: World Health Organization 1997.

[11] Poorani ES, Chandana CS. Prevalence of dental caries among chennai population. J Pharm Sci Res 2015;7(10):895-6.

[12] Patro BK, Kumar BR, Goswami A, et al. Prevalence of dental caries among adults and elderly in an urban resettlement colony of New Delhi. Indian J Dent Res 2008;19(2):95-8.

[13] Celeste RK, Nadanovsky P, De Leon AP. Association between preventive care provided in public dental services and caries prevalence. Rev Saúde Pública 2007;41(5):830-8.

[14] Gomes APM, da Silva EG, Gonçalves SHF, et al. Relationship between patient's education level and knowledge on oral health preventive measures. Int Dent Med J Adv Res 2015;1:1-7. 